\title{
Pre-hospital delay in patients with first time myocardial infarction: an observational study in a northern Swedish population
}

\author{
Gunnar Nilsson ${ }^{1 *}$, Thomas Mooe ${ }^{2}$, Lars Söderström ${ }^{3}$ and Eva Samuelsson ${ }^{2}$
}

\begin{abstract}
Background: In myocardial infarction (MI), pre-hospital delay is associated with increased mortality and decreased possibility of revascularisation. We assessed pre-hospital delay in patients with first time Ml in a northern Swedish population and identified determinants of a pre-hospital delay $\geq 2 \mathrm{~h}$.

Methods: A total of 89 women (mean age 72.6 years) and 176 men (mean age 65.8 years) from a secondary prevention study were enrolled in an observational study after first time MI between November 2009 and March 2012. Total pre-hospital delay was defined as the time from the onset of symptoms suggestive of Ml to admission to the hospital. Decision time was defined as the time from the onset of symptoms until the call to Emergency Medical Services (EMS). The time of symptom onset was assessed during the episode of care, and the time of call to EMS and admission to the hospital was based on recorded data. The first medical contact was determined from a mailed questionnaire. Determinants associated with pre-hospital delay $\geq 2 \mathrm{~h}$ were identified by multivariable logistic regression.
\end{abstract}

Results: The median total pre-hospital delay was $5.1 \mathrm{~h}$ (IQR 18.1), decision time $3.1 \mathrm{~h}$ (IQR 10.4), and transport time $1.2 \mathrm{~h}$ (IQR 1.0). The first medical contact was to primary care in $52.3 \%$ of cases $(22.3 \%$ as a visit to a general practitioner and $30 \%$ by telephone counselling), $37.3 \%$ called the EMS, and $10.4 \%$ self-referred to the hospital. Determinants of a pre-hospital delay $\geq 2 \mathrm{~h}$ were a visit to a general practitioner (OR 10.77, $95 \% \mathrm{Cl}$ 2.39-48.59), call to primary care telephone counselling (OR $3.82,95 \% \mathrm{Cl} 1.68-8.68)$, chest pain as the predominant presenting symptom (OR 0.24, $95 \% \mathrm{Cl}$ 0.08-0.77), and distance from the hospital (OR 1.03, $95 \% \mathrm{Cl} 1.02-1.04$ ). Among patients with primary care as the first medical contact, $67.0 \%$ had a decision time $\geq 2 \mathrm{~h}$, compared to $44.7 \%$ of patients who called EMS or self-referred ( $p=0.002)$.

Conclusions: Pre-hospital delay in patients with first time Ml is prolonged considerably, particularly when primary care is the first medical contact. Actions to shorten decision time and increase the use of EMS are still necessary.

Keywords: Myocardial infarction, Observational study, Pre-hospital delay, Primary care

\section{Background}

Pre-hospital delay in myocardial infarction (MI) is associated with increased mortality $[1,2]$ and decreased possibility of revascularisation $[3,4]$. Delay times exceeding $2.0 \mathrm{~h}$ are still commonly reported [5-8]. A cut-off time for pre-hospital delay is arbitrary, as mortality increases with time to reperfusion therapy $[1,9]$. However, a $2-\mathrm{h}$

\footnotetext{
*Correspondence: gunnar.nilsson@regionjh.se

'Department of Public Health and Clinical Medicine, Unit of Research,

Education and Development - Östersund, Umeå University, Umeå, Sweden

Full list of author information is available at the end of the article
}

cut-off is often applied because MI patients treated within $2 \mathrm{~h}$ receive the most clinical benefit from reperfusion therapy $[3,10]$.

Total pre-hospital delay can be divided into decision time (time from the onset of symptoms suggestive of MI until the call for medical help) and transport time (time from the call for medical help to hospital admission), also called "home-to-hospital delay" [11], with the decision time as the major part [12-15]. The scientific terminology for pre-hospital delay is not consistent; "time-to-treatment" and "treatment-seeking delay" 
are alternative terms, making comparisons between studies difficult [16].

Several determinants are associated with pre-hospital delay, including low socio-economic status, female gender, co-morbidities (e.g., diabetes and coronary disease), the patient's cognitive and emotional status, and determinants related to the healthcare provider [17, 18]. In some reports, patients with primary care as the first medical contact (FMC) have an increased pre-hospital delay [7, 19-21], often with less severe cardiac events than other patients [22]. Primary care clinics and telephone counselling services are frequently the FMC for patients with a suspected MI [7, 21], as symptoms related to MI often are not identified as cardiac [23]. Symptoms of MI may also be vague or atypical, leading to delayed care [24-27]. The impact of a previous MI on pre-hospital delay has varied in different studies. Results have shown shorter [28-31], longer [2, 32], or even neutral $[21,33]$ pre-hospital delays in association with a previous MI.

Pre-hospital delay in MI is related to the context $[22,27]$, and research on this issue should be based on data-sets that include relevant socio-demographic and healthcare-related data. The northern Swedish setting is characterised by long distances to the hospital, an aged population, and low to average education level. Traditionally, primary care has been the FMC for both acute and chronic diseases. By combining data from three different sources, we provide a more detailed picture of the pre-hospital delay issue compared to studies using a narrower data catch. Our aim was to assess the prehospital delay in men and women in a northern Swedish population with first time MI, and to identify determinants of a prolonged pre-hospital delay $\geq 2 \mathrm{~h}$.

\section{Methods}

\section{Participants}

Participants in this observational study were recruited from the population of Region Jämtland Härjedalen, northern Sweden (in 2012: population 126 201, 53 \% living in rural communities and $47 \%$ in the capital community) [34]. The capital community of the region, Östersund, is the location of the regional hospital with clinics for cardiology and emergency medical services (EMS). The distance from participants' place of residence to the hospital ranged from 0.4 to $234 \mathrm{~km}$. A referral from a GP was not required for patients to access emergency care or ambulance transport to a hospital in cases of chest pain suggestive of myocardial infarction. The primary care clinics were run by the regional healthcare authorities or contracted to provide primary care on the same taxation system and with the same patient charges. Participating patients were hospitalised with MI type 1, according to the universal definition
[35], between November 26, 2009 and March 26, 2012. Eligible participants were identified from a populationbased secondary prevention study that recruited patients after acute coronary syndromes (ACS) and stroke, within the Region Jämtland Härjedalen [36]. For patients living in rural communities, ambulance services and primary care clinics were accessible locally. Medical telephone counselling was available from primary care clinics 08:00 a.m. - 17:00 p.m. on weekdays and from Swedish Healthcare Direct (SHD) at all hours, with the possibility of directing patients to the Emergency Medical Services (EMS) or a primary care clinic as appropriate. The SHD, a part of the primary care organisation of the region, provided medical telephone counselling by nursing staff as a complementary service to the primary care clinics. The EMS alarm number was also accessible for calls from the public on a 24-h basis. The EMS with ambulance-based pre-hospital care, including thrombolytic therapy, was organised by the Emergency Care Centre, Östersund Hospital. Visits to primary care, emergency care, and ambulance transport were subject to patient charges of approximately $15-27 €$ during the study period. Deceased patients and patients declining consent or with insufficient data on pre-hospital delay were excluded from the present study.

\section{Data sources and measurements}

We used three different data sources. First, to acquire demographic and medical baseline data, a structured interview was carried out during the initial hospitalisation by nursing staff engaged in the secondary prevention study. The outline of the secondary prevention study of patients with ACS was published previously [36]. Second, previous chest pain symptoms, expectations of medical care, pre-hospital events, and FMC before admission to the hospital were recorded from a postal questionnaire sent to patients within 3-6 months after MI. Two reminders were sent to ensure participation. Third, for patients transported by ambulance, the symptoms reported by the patient at triage, the time of call to the EMS, and the time of admission to the hospital were recorded from ambulance records. For patients with private transport to the hospital, triage data and time of admission to the hospital were recorded from prospective records at the Emergency Care Centre.

Time of onset of symptoms suggestive of MI was determined during the episode of care, by nursing staff engaged in the secondary care study. Uncertainty in the time of symptom onset was estimated in hours, more or less, relative to the recorded onset time. The definitions of time intervals are explained in Fig. 1. For patients with private transport, only total pre-hospital delay was possible to calculate because the time to call to the EMS was unavailable. 
Onset of symptoms suggestive of myocardial infarction

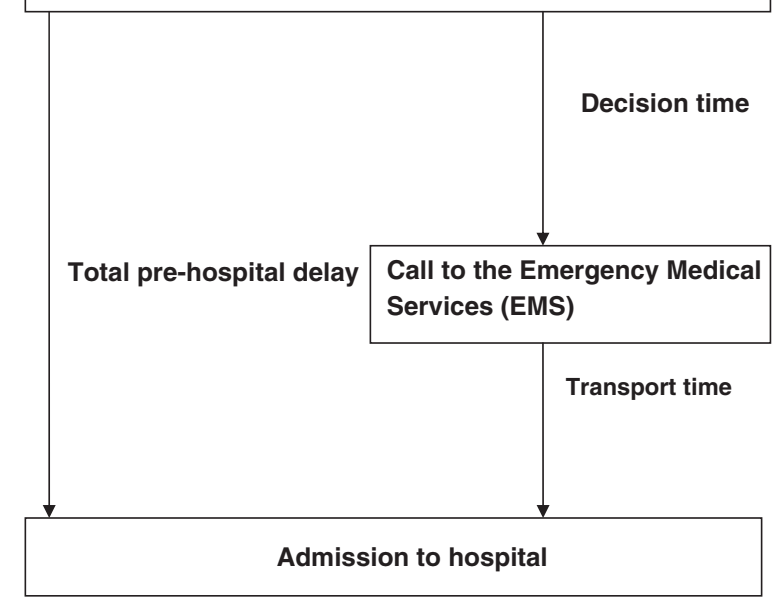

Fig. 1 Pre-hospital delay and definition of time intervals

Patients' expectations for medical care the day of admission to the hospital was assessed on a visual analogue scale from 0-100. The pain intensity at triage was assessed on a visual analogue scale from $0-10$. If several assessments of pain were recorded during triage, the highest value was chosen. If a statement of no pain was recorded, the value was recorded as 0 .

The distance from the patient's residence to the hospital was computed by Google Maps. Socio-economic classification was based on the Swedish Socioeconomic Classification (SEI) [37]. Marital status was determined from hospital records.

Three questions on previous chest pain symptoms were originally used in the "Rose angina questionnaire" [38-40] and the Swedish translation for primary care patients assessed for coronary disease [41]. Questions on the sequence of events before admission to the hospital were presented with fixed alternatives. The question "In your own opinion, did you suspect a myocardial infarction the day you fell ill?" was asked with yes and no as potential answers. A question on FMC before admission was presented with fixed alternatives, with the possibility of providing additional information, for classification into the following categories: "Personal visit to a GP before referral"; "Referral by call to a primary care centre/ Swedish Healthcare Direct"; "Called the Emergency Medical Services;" and "Self-referred to hospital". Ambulance transport of patients was confirmed by ambulance records stating the location, date, time, medical actions, and condition of the patient at triage. For patients with private transport, the same triaging procedure was carried out at the emergency department. Presenting symptoms were classified as: "Predominantly chest pain symptoms", e.g., pain, ache, burn, or pressure in the chest; "Predominantly other pain symptoms", e.g., predominance of pain in the abdomen, arm, shoulder, or neck; and "Predominance of symptoms other than pain", e.g., severe fatigue, syncope, or circulatory shock.

MIs were diagnosed in accordance with the universal definition of MI type 1 [35]. The type of MI, ST elevation MI (STEMI) or non-ST elevation MI (NSTEMI), was not treated as a determinant of pre-hospital delay because it is an outcome measurement from the prehospital perspective.

\section{Delay caused by medical misjudgement}

All medical records were scrutinised for patients who were sent home from clinics or kept waiting to detect cases in which medical misjudgement contributed to a pre-hospital delay $\geq 2 \mathrm{~h}$.

\section{Statistical analysis}

Patient characteristics are presented as proportions, means, or medians. The median and inter quartile range (IQR) were used for highly skewed distributions. To compare proportions, we used the chi-squared test or Fisher's exact test as appropriate. To compare means or medians, we used the Student's $t$-test (two sided) or the Mann-Whitney $U$-test as appropriate. We used univariate logistic regression to identify determinants of pre-hospital delay and $p<0.25$ for determinants to be included in the multivariable logistic model. We reduced the model stepwise by excluding the least significant variable manually until only significant variables remained. The level of significance was set at $p<0.05$. To assess the discriminatory power of the multivariable model, we used receiver operating characteristic (ROC) curves and calculated the area under the curve (AUC) $[42,43]$. Statistical analyses were performed in the software IBM SPSS version 22.

\section{Results \\ Descriptive data}

We recruited 265 consenting patients, 89 of which were women, to take part in this study (Fig. 2). The mean patient age was 68.1 years; the mean age of participating women was 72.6 years. "Manual workers" was the predominant socio-economic group $(62.7 \%)$. The receiving hospital for 258 patients was the central hospital in Östersund; the other seven patients were admitted to other Swedish hospitals due to temporary visits outside their normal place of residence. The FMC was primary care in $52.3 \%$ of all cases $(22.3 \%$ as a visit to a general practitioner (GP) and $30 \%$ by telephone counselling), $37.3 \%$ called the EMS, and $10.4 \%$ self-referred to the hospital. A majority of patients (76.6\%) used ambulance transport (198 by road and 5 by air ambulance). Patients visiting a GP, calling a primary care clinic/SHD, or 


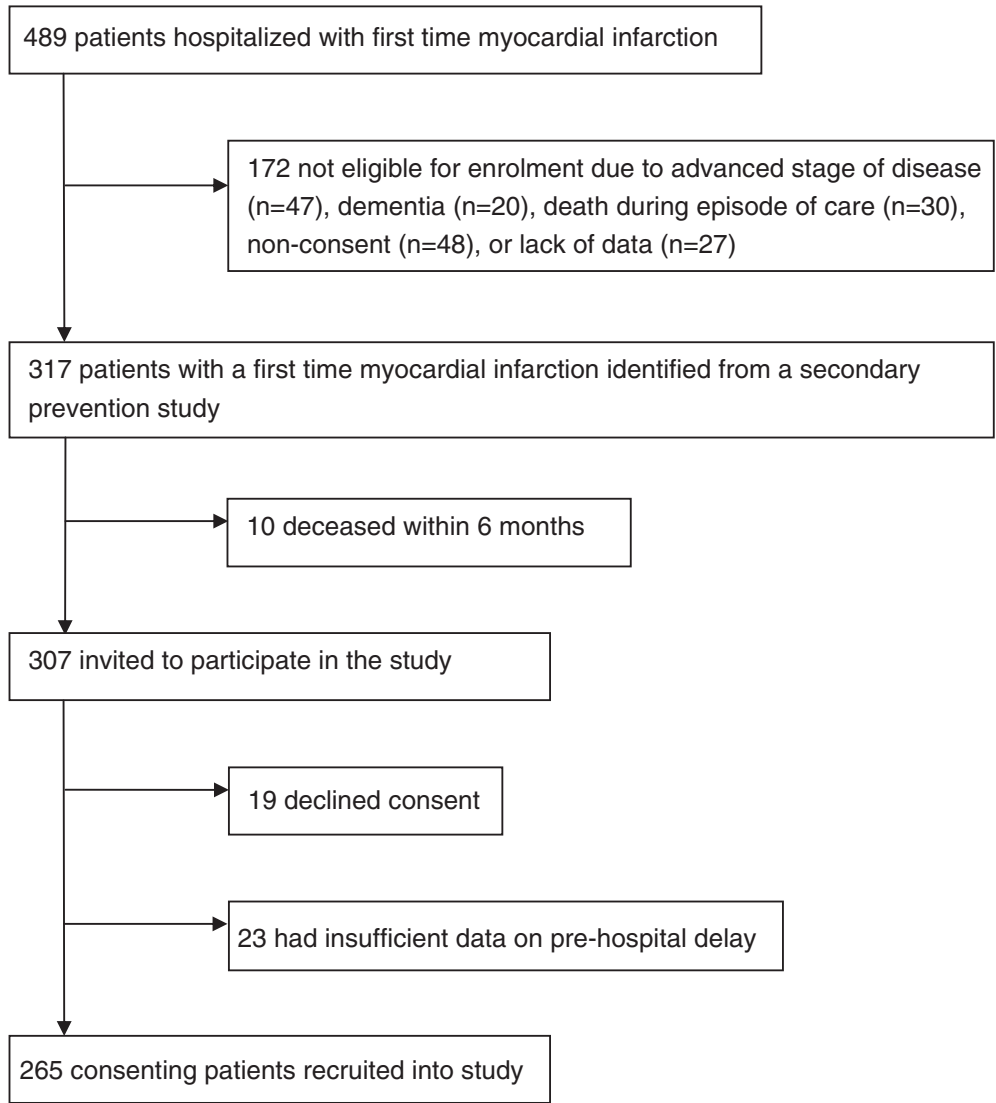

Fig. 2 Participant recruitment

calling the EMS as the FMC were transported by ambulance in 72.4, 79.5, and $99 \%$ of cases, respectively. Finally, 97 patients (36.6 \%) were diagnosed as STEMI (21 women and 76 men), and the others as NSTEMI.

\section{Main results}

The median total pre-hospital delay was 5.1 (IQR 18.1) hours, with a median decision time of 3.1 (IQR 10.4) hours and median transport time of 1.2 (IQR 1.0) hours. No differences were found between men and women (Table 1 ). The median transport time was 0.78 (IQR 0.5) hours in the central community and 1.65 (IQR 1.1) hours in the rural communities $(p<0.001)$. No significant differences were found in the decision time or total pre-hospital delay between the central and rural communities. The uncertainty of the time of symptom onset was a median $0.0 \mathrm{~h}$ (IQR 1.0), with the 80 th percentile at $2.0 \mathrm{~h}$.

A highly skewed distribution in total pre-hospital delay and decision time was observed with wide IQRs among both men and women (Table 1 and Additional file 1). Patients with a total pre-hospital delay $\geq 2 \mathrm{~h}$ lived farther from the hospital and were more likely to have consulted a GP before admission to the hospital, to be diabetic, and to report recurrent angina symptoms than those with a total pre-hospital delay $<2 \mathrm{~h}$. Patients with a total pre-hospital delay $<2 \mathrm{~h}$ were more likely to have called the EMS or self-referred to the hospital, and they were

Table 1 Total pre-hospital delay, decision time, and transport time for patients with first time myocardial infarction

\begin{tabular}{|c|c|c|c|c|}
\hline \multirow[t]{2}{*}{ Characteristic } & \multirow{2}{*}{$\begin{array}{l}\text { Total } \\
n=265\end{array}$} & \multirow{2}{*}{$\begin{array}{l}\text { Men } \\
n=176(66.4 \%)\end{array}$} & \multirow{2}{*}{$\begin{array}{l}\text { Women } \\
n=89(33.6 \%)\end{array}$} & \multirow{2}{*}{$\begin{array}{l}\text { P-value, Mann- } \\
\text { Whitney U Test }\end{array}$} \\
\hline & & & & \\
\hline Total pre-hospital delay, median (IQR) & $5.1(18.1)$ & $5.9(17.4)$ & $4.1(19.3)$ & 0.436 \\
\hline Decision time, median (IQR) ${ }^{a}$ & $3.1(10.4)$ & $3.7(10.1)$ & $2.0(11.8)$ & 0.411 \\
\hline Transport time, median (IQR) ${ }^{\mathrm{a}}$ & $1.2(1.0)$ & $1.3(1.0)$ & $1.2(1.0)$ & 0.052 \\
\hline
\end{tabular}

All data are given in hours. Total pre-hospital delay is the time between onset of symptoms suggestive of myocardial infarction and admission to the hospital. Decision time is the time between onset of symptoms suggestive of myocardial infarction and the call to Emergency Medical Services. Transport time is the time between the call to Emergency Medical Services and admission to the hospital. ${ }^{a}$ Calculated for $200 / 203$ patients transported to the hospital by ambulance 
more likely to report chest pain as the predominant symptom at triage than those with a total pre-hospital delay $\geq 2 \mathrm{~h}$ (Table 2 ).

Characteristics associated with a total pre-hospital delay $\geq 2 \mathrm{~h}$ in the adjusted model were: visit to a GP before referral (OR 10.77, $95 \%$ CI 2.39-48.59), referral by a call to a primary care centre/SHD (OR 3.82, $95 \%$ CI $1.68-8.68)$, chest pain as the predominant symptom at triage (negative association; OR 0.24, 95 \% CI $0.08-$ 0.77 ), and distance $(\mathrm{km})$ to hospital (OR 1.03, $95 \% \mathrm{CI}$ 1.02-1.04) (Table 3). Patients in contact with primary care, as a GP visit or by telephone counselling, also had a prolonged decision time (Table 3). Chest pain as the predominant symptom at triage was associated with a shorter decision time (Table 3). We examined the characteristics of the regression model for interaction with gender, but none of the findings were significant. Age, gender, and levels of scholarship did not contribute to significant improvement of the multivariable model. The discriminatory ability of the multivariable model (Table 3) was evaluated by ROC curves; the AUC was 0.84 (95 \% CI $0.79-0.90, p<0.001)$ for total pre-hospital delay and 0.68 (95\% CI 0.60-0.76, $p<0.001$ ) for decision time.

Among patients with primary care as the FMC, $67.0 \%$ had a decision time $\geq 2 \mathrm{~h}$, compared to $44.7 \%$ of patients calling the EMS or self-referring to the hospital $(p=0.002)$. Compared to patients who self-referred or called the EMS before admission to the hospital, primary care patients were younger (mean age 66.3 years (SD 12.0) vs. 69.7 (SD 10.9) years, $p=0.016)$ and lived a greater distance from the hospital (median distance $37.5 \mathrm{~km}$ (IQR 10.0-99.5) vs. $21.0 \mathrm{~km}$ (IQR 4.0-68.5), $p=$ 0.012). Patients with a FMC to primary care more often reported recurrent angina symptoms preceding the MI ( $34.6 \%$ vs. $21.8 \%, p=0.022$ ), a lower pain intensity at triage (5.1 (SD 3.1) vs. 6.3 (SD 2.9), $p=0.030$ ), and less frequently asked a friend/next of kin for help before admission to the hospital $(20.5 \%$ vs. $38.8 \%, p=0.001)$ than patients who self-referred or called the EMS. Patients with a FMC to primary care were less frequently diagnosed with STEMI than patients who self-referred or called the EMS as the FMC ( $25.7 \%$ vs. $49.2 \%, p<0.001)$. Among primary care patients with private transport to the hospital and lived in rural communities, the total prehospital delay time increased stepwise compared to the total population (Table 4).

\section{Delay caused by medical misjudgement}

We identified three patients with delayed care $\geq 2 \mathrm{~h}$ due to medical misjudgement; two were sent home from primary care clinics but returned within 12 to $24 \mathrm{~h}$, and one patient was delayed for $2 \mathrm{~h}$ at a primary care centre before referral.

\section{Non-participants}

Non-participating patients did not differ significantly with respect to age, gender, or distance from the hospital compared to participants.

\section{Discussion \\ Key findings}

The median total pre-hospital delay was $5.1 \mathrm{~h}$, with decision time as the major contributor. The FMC was to primary care (as a GP visit or by telephone counselling) in approximately half of all patients. Visiting a GP or calling primary care for telephone counselling prior to hospital admission were both associated with a total pre-hospital delay and decision time $\geq 2 \mathrm{~h}$. Chest pain as the predominant symptom at triage was associated with shorter total pre-hospital delay and decision time.

\section{Interpretation of findings}

The pre-hospital delay among our study participants exceeded that reported in several previous studies on ACS and MI. Pre-hospital delay in the European patients' study arm of the Global Registry of Acute Coronary Events (GRACE) study was a median 2.3-2.7 h for STEMI and 2.7-3.1 h for NSTEMI cases between 2000 and 2006 (lowest value in 2006) [28]. In the Northern Sweden MONICA Study, a delay time $\geq 2 \mathrm{~h}$ was found in $64 \%$ of patients with diabetes and $58 \%$ of non-diabetics [44]. In a cohort of Norwegian patients with first time MI, $52 \%$ of women and $51 \%$ of men had a total pre-hospital delay exceeding $2 \mathrm{~h}$ [19]. A pre-hospital delay similar to our data was reported in an Irish setting in 2013; the median prehospital delay for STEMI patients was $2.7 \mathrm{~h}$ and for NSTEMI patients $4.5 \mathrm{~h}$ [7].

There are several possible explanations for the prolonged delay in our study. First, unlike the MONICA cohort and the Norwegian multicentre study by Lovlien et al $[19,44]$, we did not apply an upper age limit, and we recruited a somewhat higher proportion of female participants. Second, the prolonged pre-hospital delay among our study patients is likely related to the context of medical care, as primary care as the FMC is recommended for patients and the EMS is the second choice in most circumstances [7, 19-22]. In our study, primary care as the FMC was associated with both prolonged pre-hospital delay and decision time. Pre-hospital delay attributable to healthcare provider contact was described previously $[22,30,45]$ but remains to be addressed because such provider-related delay may account for more loss in total delay time compared to patient delay [46-48]. This problem is even more important if patients believe that calling primary care, and not EMS, is always the appropriate action [49]. This could explain the association between primary care as the FMC and pre-hospital delay that we observed. 
Table 2 Characteristics of first time myocardial infarction patients according to total pre-hospital delay $(n=265)$

\begin{tabular}{|c|c|c|c|}
\hline \multirow[t]{2}{*}{ Characteristic } & \multirow{2}{*}{$\begin{array}{l}<2 \mathrm{~h} \\
n=52(19.6 \%)\end{array}$} & \multirow{2}{*}{$\begin{array}{l}\geq 2 \mathrm{~h} \\
n=213(80.4 \%)\end{array}$} & \multirow[t]{2}{*}{$P$-value } \\
\hline & & & \\
\hline Mean age, years (SD) & $67.5(11.3)$ & $68.2(11.7)$ & 0.668 \\
\hline Female sex & 19/52 (36.5 \%) & 70/213 (32.9\%) & 0.615 \\
\hline Married or cohabiting & 23/32 (71.9\%) & 106/172 (61.6 \%) & 0.270 \\
\hline Distance to hospital in km, median (IQR) & $7.0(27.5)$ & $49.8(87.4)$ & $<0.001$ \\
\hline University or college degree & $7 / 51$ (13.7\%) & $31 / 213(14.6 \%)$ & 0.880 \\
\hline Manual worker & $33 / 51(66.0 \%)$ & 132/212 (61.9\%) & 0.746 \\
\hline \multicolumn{4}{|l|}{ Medical history } \\
\hline Previous revascularisation & $2 / 52(3.8 \%)$ & 7/213 (3.3\%) & 0.691 \\
\hline Previous stroke or TIA & $3 / 52(5.8 \%)$ & 10/213 (4.7\%) & 0.742 \\
\hline Angina pectoris, current diagnosis & $2 / 52(3.8 \%)$ & 20/213 (9.4 \%) & 0.267 \\
\hline Hypertension, current diagnosis & $25 / 5248.1 \%)$ & 104/213 (48.8 \%) & 0.923 \\
\hline Diabetes mellitus, medication for & $5 / 52(9.6 \%)$ & $46 / 213(21.6 \%)$ & 0.049 \\
\hline Dyslipidaemia, medication for & 6/52 (11.5\%) & 44/213 (20.7\%) & 0.132 \\
\hline \multicolumn{4}{|l|}{ Previous chest pain symptoms } \\
\hline Ever have chest pain or discomfort in the chest & $21 / 52(40.4 \%)$ & $63 / 203(31.0 \%)$ & 0.201 \\
\hline Chest pain walking at an ordinary pace on the level & $3 / 51(5.9 \%)$ & 23/198 (11.6\%) & 0.232 \\
\hline Chest pain walking uphill or in a hurry & $14 / 51(27.5 \%)$ & 68/202 (33.7 \%) & 0.397 \\
\hline \multicolumn{4}{|l|}{ On the day of admission to hospital } \\
\hline Myocardial infarction suspected by patient & 23/52 (44.2 \%) & $71 / 210(33.8 \%)$ & 0.161 \\
\hline "I decided by myself to seek medical care" & 23/49 (46.9 \%) & 99/209 (47.47.4\%) & 0.957 \\
\hline "I took advice from a next of kin/friend" & 9/49 (18.4\%) & $50 / 209(23.9 \%)$ & 0.405 \\
\hline "A next of kin/friend contacted medical care" & $17 / 49(34.7 \%)$ & $60 / 209(28.7 \%)$ & 0.410 \\
\hline Expectations of medical care, mean (SD) ${ }^{\mathrm{a}}$ & $80.2(15.0)$ & $76.2(21.4)$ & 0.208 \\
\hline \multicolumn{4}{|l|}{ First medical contact before admission to hospital } \\
\hline Personal visit to a GP before referral & $2 / 52(3.8 \%)$ & $56 / 208(26.9 \%)$ & $<0.001$ \\
\hline Referred by call to a primary care centre/Swedish Healthcare Direct & 10/52 (19.2\%) & $68 / 208(32.7 \%)$ & 0.058 \\
\hline Called the Emergency Medical Services & $27 / 52(51.9 \%)$ & 70/208 (33.7 \%) & 0.015 \\
\hline Self-referred to hospital & $13 / 52(25.0 \%)$ & 14/208 (6.7\%) & $<0.001$ \\
\hline Ambulance transport to hospital & $36 / 52(69.2 \%)$ & 167/213 (78.4 \%) & 0.161 \\
\hline \multicolumn{4}{|l|}{ Symptoms reported by patient at triage } \\
\hline Predominantly chest pain & $48 / 52(92.3 \%)$ & 170/211 (80.6\%) & 0.044 \\
\hline Predominantly other pain & $3 / 52(5.8 \%)$ & $27 / 211(12.8 \%)$ & 0.153 \\
\hline Symptoms other than pain predominated & $1 / 52(1.9 \%)$ & 14/211 (6.6 \%) & 0.189 \\
\hline Symptom onset related to physical strain & 10/52 (19.2 \%) & $37 / 210(17.6 \%)$ & 0.786 \\
\hline Recurrent angina within 2 weeks before admission & 9/52 (17.3\%) & 69/213 (32.4\%) & 0.032 \\
\hline Pain intensity, mean $(S D)^{b}$ & $6.7(2.7)$ & $5.5(3.1)$ & 0.099 \\
\hline
\end{tabular}

TIA transitory ischaemic attack

${ }^{a}$ Visual analogue scale from 0 to 100 where 0 is lowest and 100 is highest possible expectations; five patients with missing values

${ }^{b}$ Visual analogue scale from 0 to 10 where 0 is no pain and 10 is worst possible pain; assessed at triage in 115/265 patients

Furthermore, many of our study participants lived far from the hospital, with consequences on transport time. However, $76.6 \%$ used an ambulance for transportation to the hospital, which is a greater proportion of patients than in previous reports from Ireland, Australia, and
Sweden (40-50 \% of ACS patients with ambulance transport) [50-52]. Among our patients, $37.3 \%$ primarily called the EMS, $99 \%$ of which were transported by ambulance, compared to $72.4 \%$ of patients who visited a GP as the FMC. GP visits before hospital admission may 
Table 3 Characteristics associated with prolonged pre-hospital delay in patients with first time myocardial infarction

\begin{tabular}{llllll}
\hline Characteristic & \multicolumn{2}{l}{ Total prehospital delay $\geq 2 \mathrm{~h}$} & & Decision time $\geq 2 \mathrm{~h}$ \\
\cline { 2 - 3 } & Adjusted OR (95\% Cl) & $P$-value & & Adjusted OR (95\% Cl) & $P$-value \\
\hline Personal visit to a GP before referral & $10.77(2.39-48.59)$ & 0.002 & $3.85(1.66-8.90)$ & 0.002 \\
Referred by call to a primary care centre/Swedish Healthcare Direct & $3.82(1.68-8.68)$ & 0.001 & $2.00(1.03-3.87)$ & 0.041 \\
Chest pain predominating symptom at triage & $0.24(0.08-0.77)$ & 0.016 & $0.34(0.12-0.90)$ & 0.031 \\
Distance to hospital, km & $1.03(1.02-1.04)$ & $<0.001$ & $1.00(1.00-1.01)$ & 0.586 \\
\hline
\end{tabular}

Total pre-hospital delay is the time between onset of symptoms suggestive of myocardial infarction and admission to the hospital. Decision time is the time between onset of symptoms suggestive of myocardial infarction and the call to Emergency Medical Services

have resulted in delayed transport and fewer patients transported by ambulance, as recently reported in an Irish setting [51]. Ambulance stations with access to thrombolytic therapy were located in all rural communities, and a shortage of ambulance resources is unlikely to have contributed to delayed care among our patients.

In our study, the average education level was low and a majority of participants were manual workers, but these were not determinants of pre-hospital delay. Previous research has demonstrated a relationship between low socio-economic level and pre-hospital delay [18, 53, 54], but definitions of socio-economic status and cut-offs for pre-hospital delay differ, making comparisons difficult.

\section{Future aspects}

The association between the patient's choice of FMC and pre-hospital delay force us to rethink the kind of assessment of chest pain that is most appropriate in primary care. Clinical prediction rules to rule out coronary disease in low-risk patients has been proposed as one possibility for selecting patients with chest pain for cardiologic care $[55,56]$; point-of-care troponin $\mathrm{T}$ testing is another possibility [57], but such measures are unlikely to decrease pre-hospital delay related to health care providers. As proposed previously, medical telephone counselling should be the focus of an epidemiological study to further develop the management of ACS calls [22]. Our findings support patients with new onset chest pain being encouraged to call the EMS and not primary care telephone counselling. As public campaigns to reduce

Table 4 Total pre-hospital delay according to first medical contact (FMC), transport mode, and residency

\begin{tabular}{lll}
\hline Characteristic & $\begin{array}{l}\text { Number of } \\
\text { patients }\end{array}$ & $\begin{array}{l}\text { Total pre-hospital } \\
\text { delay in hours, } \\
\text { median (IQR) }\end{array}$ \\
\hline Total & 265 & $5.1(18.1)$ \\
Primary care as FMC & 136 & $8.7(33.3)$ \\
$\begin{array}{l}\text { Primary care as FMC and private } \\
\text { transport to hospital }\end{array}$ & 32 & $20.9(69.1)$ \\
$\begin{array}{l}\text { Primary care as FMC, private transport } \\
\text { to hospital, and rural residency }\end{array}$ & 12 & $74.0(140.8)$ \\
\hline
\end{tabular}

Primary care as FMC: Visit to a GP, call to a primary care centre or Swedish Healthcare Direct pre-hospital delay have yielded negative results [58], future efforts should target high-risk patients, preferably by individualised patient education, which has been reported to reduce pre-hospital time in patients with recurrent ACS episodes [15]. A high-risk approach is further supported by the increasing delay-time among certain subgroups in our study, such as primary care patients with private transport to the hospital and rural residency (Table 4). The discriminatory ability of the multivariable model supports the core determinants of pre-hospital delay being related to a patient's decision-making process and choice of health care provider $[22,46]$.

\section{Strengths and limitations}

We used different data sources to provide detailed information on each study participant. A high participation rate $(86.3 \%)$ and the population-based study approach strengthened the external validity. Data on symptom presentation at triage were recorded from ambulance and emergency care records, reflecting conditions at the time of care as closely as possible. Previous medical history, socio-economic status, and time of symptom onset were assessed by trained nursing staff during the episode of care. The exact time of the onset of symptoms indicating MI can be hard to establish and is a common problem in studies reporting on pre-hospital delay [16]. An estimation of the uncertainty in the time of symptom onset was included in our study plan.

The subdivision of total pre-hospital delay into decision time and transport time was not possible to calculate in patients with private transport to the hospital, which limits our analysis of decision time and transport time to patients with ambulance transport. Delay due to medical misjudgement was determined from retrospective data, which may have been insufficient. We recruited patients from a population-based secondary prevention program after MI and ACS, meaning that the generalisability of our findings is limited to surviving patients eligible for a prevention programme. The rural context, with many patients living distantly from hospital but with access to primary care and ambulance services, is another limitation for the overall generalisability of our findings. The postal questionnaire covering previous 
chest pain symptoms, sequence of events, and FMC prior to hospitalisation was delivered within 3-6 months after the MI, and recall bias cannot be ruled out.

Comparisons across different studies are complicated by different definitions of pre-hospital delay [16]. We applied a bivariate approach with a 2-h cut-off to identify determinants associated with pre-hospital delay. This time limit was chosen from a theoretical point of view [3] and to allow comparisons with other studies using the same cut-off $[14,19,28,44,59]$.

\section{Conclusions}

In this study of patients in a northern Swedish population with first time MI, the total pre-hospital delay was considerably prolonged (median $5.1 \mathrm{~h}$ ), with decision time as the major contributor (median $3.1 \mathrm{~h}$ ). Primary care patients had a longer pre-hospital delay, mainly due to a longer decision time. Actions to shorten decision time and increase the use of EMS are still necessary.

\section{Ethics approval and consent to participate}

The study was approved by the Regional Ethics Review Board, Umeå University (reference number Dnr 09-133 M and 2010/302-32 M). All participants provided written informed consent.

\section{Consent for publication}

Not applicable.

\section{Availability of data and materials}

Patient level data will be available on request, provided that an approval is given from the Regional Ethics Review Board at Umeå University, Sweden.

\section{Additional file}

Additional file 1: Box plots of total pre-hospital delay and decision time. (PDF $171 \mathrm{~kb})$

\section{Abbreviations}

ACS: Acute coronary syndrome; AUC: Area under the curve; ECG: Electrocardiogram; EMS: Emergency medical services; FMC: First medical contact; GP: General Practitioner; MI: Myocardial infarction; NSTEMI: Non-ST elevation myocardial infarction; ROC: Receiver operating characteristic; SHD: Swedish Healthcare Direct; STEMI: ST elevation myocardial infarction.

\section{Competing interests}

The authors declare that they have no competing interests.

\section{Authors' contributions}

GN designed the study, performed the statistical analyses, and drafted the manuscript. ES supervised the study design, participated in data analysis, and helped draft the manuscript. TM supervised the study design, participated in data analysis, and helped draft the manuscript. LS gave advice on the statistical analyses, participated in data analysis, and helped draft the manuscript. All authors read and approved the final manuscript.

\section{Authors' information}

GN: GP, doctoral student, Department of Public Health and Clinical Medicine, Unit of Research, Education and Development - Östersund, Umeå University, Sweden.

ES: GP, Associate Professor, Family Medicine, Department of Public Health and Clinical Medicine, Umeå University, Sweden.

TM: Consultant in cardiology, Östersund Hospital, Associate Professor of Medicine, Department of Public Health and Clinical Medicine, Umeå University, Sweden.

LS: Master of Science, Unit of Research, Education and Development -

Östersund Hospital, Östersund, Sweden.

\section{Acknowledgements}

The authors wish to express their sincere gratitude to all study participants and the staff engaged in the Nailed ACS Risk Factor Trial.

\section{Funding}

This study was funded by grants from the Unit of Research, Education and Development, Östersund Hospital, Region Jämtland Härjedalen, Sweden (Dnr-JLL- 370941, 368631 and 467081). The funders had no role in the study design, data collection, data analysis, or in writing of the report.

\section{Author details}

'Department of Public Health and Clinical Medicine, Unit of Research, Education and Development - Östersund, Umeå University, Umeå, Sweden. 2Department of Public Health and Clinical Medicine, Umeå University, Umeå, Sweden. ${ }^{3}$ Unit of Research, Education and Development, Östersund Hospital, Region Jämtland Härjedalen, Östersund, Sweden.

Received: 26 August 2015 Accepted: 4 May 2016

Published online: 12 May 2016

\section{References}

1. De Luca G, Suryapranata H, Ottervanger JP, Antman EM. Time delay to treatment and mortality in primary angioplasty for acute myocardial infarction: every minute of delay counts. Circulation. 2004;109(10):1223-5.

2. Newby LK, Rutsch WR, Califf RM, Simoons ML, Aylward PE, Armstrong PW, et al. Time from symptom onset to treatment and outcomes after thrombolytic therapy. GUSTO-1 Investigators. J Am Coll Cardiol. 1996;27(7): 1646-55.

3. Goldberg RJ, Mooradd M, Gurwitz JH, Rogers WJ, French WJ, Barron HV, et al. Impact of time to treatment with tissue plasminogen activator on morbidity and mortality following acute myocardial infarction (The second National Registry of Myocardial Infarction). Am J Cardiol. 1998;82(3):259-64.

4. Kushner FG, Hand M, Smith Jr SC, King III SB, Anderson JL, Antman EM, et al. focused updates: ACC/AHA guidelines for the management of patients with ST-elevation myocardial infarction (updating the 2004 guideline and 2007 focused update) and ACC/AHA/SCAl guidelines on percutaneous coronary intervention (updating the 2005 guideline and 2007 focused update) a report of the American College of Cardiology Foundation/American Heart Association Task Force on Practice Guidelines. J Am Coll Cardiol. 2009; 54(23):2205-41.

5. Goldberg RJ, Steg PG, Sadiq I, Granger CB, Jackson EA, Budaj A, et al. Extent of, and factors associated with, delay to hospital presentation in patients with acute coronary disease (the GRACE registry). American J Cardiol. 2002; 89(7):791-6.

6. Isaksson RM, Holmgren L, Lundblad D, Brulin C, Eliasson M. Time trends in symptoms and prehospital delay time in women vs. men with myocardial infarction over a 15-year period. The Northern Sweden MONICA Study. Eur J Cardiovasc Nurs. 2008;7(2):152-8.

7. McKee G, Mooney M, O'Donnell S, O'Brien F, Biddle MJ, Moser DK. Multivariate analysis of predictors of pre-hospital delay in acute coronary syndrome. Int J Cardiol. 2013;168(3):2706-13.

8. Saczynski JS, Yarzebski J, Lessard D, Spencer FA, Gurwitz JH, Gore JM, et al. Trends in prehospital delay in patients with acute myocardial infarction (from the Worcester Heart Attack Study). Am J Cardiol. 2008;102(12):1589-94.

9. Estevez-Loureiro R, Lopez-Sainz A, Perez de Prado A, Cuellas C, Calvino Santos $\mathrm{R}$, Alonso-Orcajo $\mathrm{N}$, et al. Timely reperfusion for ST-segment elevation myocardial infarction: Effect of direct transfer to primary angioplasty on time delays and clinical outcomes. World J Cardiol. 2014;6(6):424-33. 
10. Chareonthaitawee P, Gibbons RJ, Roberts RS, Christian TF, Burns R, Yusuf S. The impact of time to thrombolytic treatment on outcome in patients with acute myocardial infarction. For the CORE investigators (Collaborative Organisation for RheothRx Evaluation). Heart. 2000;84(2):142-8.

11. Perkins-Porras L, Whitehead DL, Strike PC, Steptoe A. Pre-hospital delay in patients with acute coronary syndrome: factors associated with patient decision time and home-to-hospital delay. Eur J Cardiovasc Nurs. 2009;8(1):26-33.

12. Moss AJ, Goldstein S. The pre-hospital phase of acute myocadial infarction. Circulation. 1970;41(5):737-42.

13. Ottesen MM, Dixen U, Torp-Pedersen C, Kober L. Prehospital delay in acute coronary syndrome-an analysis of the components of delay. Int J Cardiol. 2004;96(1):97-103.

14. Rasmussen CH, Munck A, Kragstrup J, Haghfelt T. Patient delay from onset of chest pain suggesting acute coronary syndrome to hospital admission. Scand Cardiovasc J. 2003;37(4):183-6.

15. Mooney M, McKee G, Fealy G, O' Brien F, O'Donnell S, Moser D. A randomized controlled trial to reduce prehospital delay time in patients with acute coronary syndrome (ACS). J Emerg Med. 2014;46(4):495-506.

16. Mackay MH, Ratner PA, Nguyen M, Percy M, Galdas P, Grunau G. Inconsistent measurement of acute coronary syndrome patients' pre-hospital delay in research: a review of the literature. Eur J Cardiovasc Nurs. 2014;13(6):483-93.

17. Khraim FM, Carey MG. Predictors of pre-hospital delay among patients with acute myocardial infarction. Patient Educ Couns. 2009;75(2):155-61.

18. Moser DK, Kimble LP, Alberts MJ, Alonzo A, Croft JB, Dracup K, et al. Reducing delay in seeking treatment by patients with acute coronary syndrome and stroke: a scientific statement from the American Heart Association Council on cardiovascular nursing and stroke council. Circulation. 2006;114(2):168-82.

19. Lovlien M, Schei B, Hole T. Prehospital delay, contributing aspects and responses to symptoms among Norwegian women and men with first time acute myocardial infarction. Eur J Cardiovasc Nurs. 2007;6(4):308-13.

20. O'Donnell S, Condell S, Begley C, Fitzgerald T. Prehospital care pathway delays: gender and myocardial infarction. J Adv Nurs. 2006;53(3):268-76.

21. Johansson I, Stromberg A, Swahn E. Factors related to delay times in patients with suspected acute myocardial infarction. Heart Lung. 2004; 33(5):291-300

22. Alonzo AA. The effect of health care provider consultation on acute coronary syndrome care-seeking delay. Heart Lung. 2007;36(5):307-18.

23. Tummala SR, Farshid A. Patients' understanding of their heart attack and the impact of exposure to a media campaign on pre-hospital time. Heart Lung Circ. 2015:24(1):4-10.

24. Isaksson RM, Brulin C, Eliasson M, Naslund U, Zingmark K. Prehospital experiences of older men with a first myocardial infarction: a qualitative analysis within the Northern Sweden MONICA Study. Scand J Caring Sci. 2011;25(4):787-97.

25. Isaksson RM, Brulin C, Eliasson M, Naslund U, Zingmark K. Older women's prehospital experiences of their first myocardial infarction. J Cardiovasc Nurs. 2013;28(4):360-9.

26. Kirchberger I, Heier M, Wende R, von Scheidt W, Meisinger $C$. The patient's interpretation of myocardial infarction symptoms and its role in the decision process to seek treatment: the MONICA/KORA Myocardial Infarction Registry. Clin Res Cardiol. 2012;101(11):909-16.

27. Pattenden J, Watt I, Lewin RJ, Stanford N. Decision making processes in people with symptoms of acute myocardial infarction: qualitative study. BMJ. 2002;324(7344):1006-9.

28. Goldberg RJ, Spencer FA, Fox KA, Brieger D, Steg PG, Gurfinkel E, et al. Prehospital Delay in Patients With Acute Coronary Syndromes (from the Global Registry of Acute Coronary Events [GRACE]). Am J Cardiol. 2009; 103(5):598-603.

29. Meischke H, Larsen MP, Eisenberg MS. Gender differences in reported symptoms for acute myocardial infarction: impact on prehospital delay time interval. Am J Emerg Med. 1998;16(4):363-6.

30. Sheifer SE, Rathore SS, Gersh BJ, Weinfurt KP, Oetgen WJ, Breall JA, et al. Time to presentation with acute myocardial infarction in the elderly: associations with race, sex, and socioeconomic characteristics. Circulation. 2000;102(14):1651-6.

31. Leizorovicz A, Haugh MC, Mercier C, Boissel JP. Pre-hospital and hospital time delays in thrombolytic treatment in patients with suspected acute myocardial infarction. Analysis of data from the EMIP study. European Myocardial Infarction Project. Eur Heart J. 1997;18(2):248-53.

32. Yarzebski J, Goldberg RJ, Gore JM, Alpert JS. Temporal trends and factors associated with extent of delay to hospital arrival in patients with acute myocardial infarction: the Worcester Heart Attack Study. Am Heart J. 1994 128(2):255-63.

33. Dracup K, Moser DK, Eisenberg M, Meischke H, Alonzo AA, Braslow A. Causes of delay in seeking treatment for heart attack symptoms. Soc Sci Med. 1995;40(3):379-92.

34. Statistical database. Statistics Sweden. 2015. http://www.statistikdatabasen. scb.se/. Accessed 25 Aug 2015.

35. Thygesen K, Alpert JS, White HD. Universal definition of myocardial infarction Eur Heart J. 2007;28(20):2525-38.

36. Mooe T, Bjorklund F, Graipe A, Huber D, Jakobsson S, Kajermo U, et al. The Nurse-Based Age Independent Intervention to Limit Evolution of Disease After Acute Coronary Syndrome (NAILED ACS) Risk Factor Trial: Protocol for a Randomized Controlled Trial. JMIR Res Protoc. 2014;3(3):e42.

37. Statistics Sweden. Swedish socio-economic classification (SEI). In: Reports on Statistical Co-ordination 1982:4. http://www.scb.se/Grupp/Hitta_statistik/Forsta_ Statistik/Klassifikationer/_Dokument/SEl-AGG_Eng.pdf. Accessed 25 Aug 2015.

38. Lawlor DA, Adamson J, Ebrahim S. Performance of the WHO Rose angina questionnaire in post-menopausal women: are all of the questions necessary? J Epidemiol Community Health. 2003;57(7):538-41.

39. Rose G, McCartney P, Reid DD. Self-administration of a questionnaire on chest pain and intermittent claudication. Br J Prev Soc Med. 1977:31(1):42-8

40. Rose GA. The diagnosis of ischaemic heart pain and intermittent claudication in field surveys. Bull World Health Organ. 1962;27:645-58.

41. Nilsson G, Mooe T, Stenlund H, Samuelsson E. Diagnostic characteristics and prognoses of primary-care patients referred for clinical exercise testing: a prospective observational study. BMC Fam Pract. 2014;15:71.

42. Fan J, Upadhye S, Worster A. Understanding receiver operating characteristic (ROC) curves. CJEM. 2006:8(1):19-20.

43. Faraggi D, Reiser B. Estimation of the area under the ROC curve. Stat Med. 2002;21(20):3093-106

44. Angerud KH, Brulin C, Naslund U, Eliasson M. Longer pre-hospital delay in first myocardial infarction among patients with diabetes: an analysis of 4266 patients in the northern Sweden MONICA Study. BMC Cardiovasc Disord. 2013;13:6

45. GISSI-Avoidable Delay Study Group. Epidemiology of avoidable delay in the care of patients with acute myocardial infarction in Italy. A GISSI-generated study. Arch Intern Med. 1995;155(14):1481-8.

46. Alonzo AA. The impact of physician consultation on care-seeking during acute episodes of coronary heart disease. Med Care. 1977;15(1):34-50.

47. Bouma J, Broer J, Bleeker J, van Sonderen E, Meyboom-de Jong B, DeJongste MJ. Longer pre-hospital delay in acute myocardial infarction in women because of longer doctor decision time. J Epidemiol Community Health. 1999;53(8):459-64.

48. Broer J, Bleeker JK, Bouma J, de Jongste MJ, Erdman RA, Meyboom-de JB. Regional differences in prehospital time delay for patients with acute myocardial infarction; Rotterdam and Groningen, 1990-1995. Ned Tijdschr Geneeskd. 2000;144(2):78-83.

49. Leslie WS, Urie A, Hooper J, Morrison CE. Delay in calling for help during myocardial infarction: reasons for the delay and subsequent pattern of accessing care. Heart. 2000;84(2):137-41.

50. Kerr D, Holden D, Smith J, Kelly AM, Bunker S. Predictors of ambulance use in patients with acute myocardial infarction in Australia. Emerg Med J. 2006; 23(12):948-52.

51. Mooney M, O'Brien F, McKee G, O'Donnell S, Moser D. Ambulance use in acute coronary syndrome in Ireland: a cross-sectional study. Eur J Cardiovasc Nurs. 2015; doi:10.1177/1474515115579134.

52. Thuresson M, Jarlov MB, Lindahl B, Svensson L, Zedigh C, Herlitz J. Factors that influence the use of ambulance in acute coronary syndrome. Am Heart J. 2008;156(1):170-6

53. Lovlien M, Schei B, Hole T. Myocardial infarction: psychosocial aspects, gender differences and impact on pre-hospital delay. J Advanc Nurs. 2008, 63(2):148-54.

54. Park YH, Kang GH, Song BG, Chun WJ, Lee JH, Hwang SY, et al. Factors related to prehospital time delay in acute ST-segment elevation myocardial infarction. J Korean Med Sci. 2012;27(8):864-9.

55. Bosner S, Becker A, Abu Hani M, Keller H, Sonnichsen AC, Haasenritter J, et al. Accuracy of symptoms and signs for coronary heart disease assessed in primary care. Br J Gen Pract. 2010;60(575):e246-57.

56. Gencer B, Vaucher P, Herzig L, Verdon F, Ruffieux C, Bosner S, et al. Ruling out coronary heart disease in primary care patients with chest pain: a clinical prediction score. BMC Med. 2010;8:9. 
57. Nilsson S, Andersson PO, Borgquist L, Grodzinsky E, Janzon M, Kvick M, et al. Point-of-Care Troponin T Testing in the Management of Patients with Chest Pain in the Swedish Primary Care. Int J Family Med. 2013;2013:532093.

58. Dracup K, McKinley S, Riegel B, Moser DK, Meischke H, Doering LV, et al. A randomized clinical trial to reduce patient prehospital delay to treatment in acute coronary syndrome. Circ Cardiovasc Qual Outcomes. 2009;2(6):524-32.

59. Ting HH, Bradley EH, Wang Y, Lichtman JH, Nallamothu BK, Sullivan MD, et al. Factors associated with longer time from symptom onset to hospital presentation for patients with ST-elevation myocardial infarction. Arch Intern Med. 2008;168(9):959-68.

Submit your next manuscript to BioMed Central and we will help you at every step:

- We accept pre-submission inquiries

- Our selector tool helps you to find the most relevant journal

- We provide round the clock customer support

- Convenient online submission

- Thorough peer review

- Inclusion in PubMed and all major indexing services

- Maximum visibility for your research

Submit your manuscript at www.biomedcentral.com/submit
Biomed Central 